EPiC Series in Language and Linguistics
Volume 2, 2017, Pages 148-158
Professional and Academic Discourse:
an Interdisciplinary Perspective

\title{
Clitic Doubling in Majorcan Spanish and Catalan
}

\author{
Amelia Jiménez-Gaspar ${ }^{1}$, Pedro Guijarro-Fuentes ${ }^{1}$ and Acrisio Pires ${ }^{2}$ \\ ${ }^{1}$ Universidad de las Islas Baleares, Palma de Mallorca, Spain; \\ ${ }^{2}$ University of Michigan, Ann Arbor, United States \\ amelia.jimenez@uib.es, p.guijarr@uib.es, pires@umich.edu
}

\begin{abstract}
In this study, we focus on clitic doubling with a human or animate referent. We attempt to determine whether or not bilingual Catalan-Spanish speakers (from Mallorca, Spain) employ the corresponding preposition (so-called personal a) in this type of clitic doubling structure in Spanish and in Catalan. In addition, we consider the use of thirdperson [ \pm human] pronominal, non-reflexive clitics, both for direct and indirect object.

We present results from a study of forty bilingual speakers from Mallorca. The data we analyzed came from spontaneous oral production data from all the participants in the study. Each participant was recorded twice, once in Spanish and once in the Majorcan Catalan variety. Each recording consisted of interviews with the researcher involving a variety of topics and lasted approximately 10 to 15 minutes.

The preliminary results indicate that in Majorcan Spanish there are no substantial differences compared to Peninsular Spanish regarding the use of third person, nonreflexive clitics. Regarding the Majorcan Catalan uses, the results are also not so different in comparison to Peninsular Catalan, but we see a substantial increase in the rate of distinct uses of the neutral clitic ho. However, when third-person clitics are used in a clitic doubling structure in Spanish there is a difference between L1 speakers of Catalan and L1 speakers of Spanish. This is because the former tend to omit the preposition in the corresponding DP.
\end{abstract}

\section{Introduction $^{1}$}

Literature on the Spanish spoken in Mallorca is minimal (e.g. Sinner \& Wesch 2008). Regarding the production of clitics, there are no references concerning the phenomena of leísmo (use of dative clitics

\footnotetext{
${ }^{1}$ We are grateful to Natascha Müller and Laia Arnaus Gil for allowing us to use part of their data as our monolingual control group. We are also thankful to audiences at AESLA (2016), AEAL (2016) and the $8^{\text {th }}$ WSS (2016) for their feedback on presentations about this project. Thanks to the last author's RA, Annika Topelian for help proofreading this paper.
} 
in the place of accusative clitics) and laísmo, or loísmo (use of accusative clitics instead of dative clitics), in Mallorca. The same is true of Catalan, for which there are several studies on clitics, but the literature focuses especially on the peninsular varieties (Fischer 2003); again the references are minimal to the use of Majorcan Catalan (Perea 2012). With regard to what is known about clitic doubling, there is no previous research on what can occur in the grammar of bilingual speakers of these two linguistic varieties (Spanish-Catalan). In this study, we analyze what happens with the corresponding preposition $a$ in clitic doubling structures with human or animate referents.

Roca (1992) points out that, no matter what syntactic approach one takes to analyze third-person clitics as direct objects (DO) and indirect objects (IO), what really matters is not to analyze these two types of clitic equivalently. Crucially, despite having many similarities, they differ in the case of clitic doubling. One of the most important differences between IO and DO clitics is that the IO clitics have no gender differences, unlike DO clitics, which have the same agreement $(\phi$-)features as strong pronouns, that is, person, gender, and number specification (Table 1):

\begin{tabular}{lllc}
\hline & & DO clitics & IO clitics \\
\hline Singular & lo & la & le \\
\hline Plural & los & las & les \\
\hline
\end{tabular}

Table 1: Direct and indirect object clitics in Spanish (etymological system)

This paper is organized as follows: in sections 2 and 3 we present the phenomena considered in this study; in section 4 we present our research questions, hypotheses and the methodology. Sections 5 and 6 present our results. Finally, the last section is a summary with our final remarks.

\section{Clitic Doubling and the use of the Personal Preposition $a$}

"Clitic doubling is a construction in which a clitic co-occurs with a full DP in argument position forming a discontinuous constituent with it" (Anagnostopoulou 2006). We present an example in (1):

$\begin{array}{llll}\text { (1) Le } & \text { gusta } & \text { el chocolate } & \text { a él } \\ \text { 3p-dat } & \text { like-3-p-sing } & \text { chocolate } & \text { to him }\end{array}$

\section{'He likes the chocolate'}

One of the most important differences in these constructions with respect to the direct and the indirect object is that the latter always allows the clitic doubling structure, while the direct object has some restrictions, e.g. (2) vs. (3) (Roca 1992):

(2) Luis le dio un libro a María

L. 3p.cl-dat gave a book to M.

'Luis gave María a book'

(3) * Luis la vio a María

Luis 3p.acc-fem.cl saw to María

'Luis saw Maria.'

In clitic doubling with a strong pronoun in a DP, the presence of the clitic is obligatory (4)-(5):
a. Lo vi a él
3p.acc-masc.cl (I) saw to him
'I saw him'

b. *vi a él

a. Le devolví el libro a ella

3p.cl-dat (I) returned the book to her

'I returned the book to her'

b. *devolví el libro a ella. 
In Catalan, unlike in Spanish, a preposition is not used in direct objects with some verbs, although the objects refer to a [+human] or [+animate] object:

(6) En Joan va saludar la seva germana (Cat.)

Juan saludó a su hermana (Sp.)

'John greeted his/her sister'

\section{Etymological Clitic Uses vs. Referential Clitic Uses}

There are two possible pronominal systems in Spanish, referred to as the etymological (Table 1), characterized by differential case (accusative, dative), and the referential (Table 2), which does not follow distinctions of case but only gender (masculine and feminine) and number. It is also possible for an etymological system of pronominal clitics to be used in parallel to a referential system, as in Spanish dialects in contact with Basque (Urrutia Cárdenas \& Ulloa 1997), among others.

\begin{tabular}{|c|c|c|c|c|c|}
\hline \multirow{3}{*}{$\begin{array}{l}\text { Accusative } \\
\text { and dative }\end{array}$} & \multicolumn{4}{|c|}{ Discontinuous } & \multirow{3}{*}{$\begin{array}{c}\text { Continuous } \\
\text { lo }\end{array}$} \\
\hline & \multicolumn{2}{|c|}{ Singular } & \multicolumn{2}{|c|}{ Plural } & \\
\hline & Masculine & Feminine & Masculine & Feminine & \\
\hline & le & la & los/les & las & \\
\hline
\end{tabular}

Table 2: Spanish referential pronominal system (Fernández-Ordóñez 2001:12)

However, there are no studies which refer to the possible use of the referential forms instead of etymological ones in the Balearic Islands. That is, it is understood that these islands are not considered leístas, laístas, or loístas, unlike the center of the Peninsula. Concerning the Catalan third-person clitics, different authors (e.g. Todolí 1998) only present the etymological system, which depend on the Latin cases:

\begin{tabular}{lcccc}
\hline Latin cases & Masculine & Feminine & Neutral & Syntactic function \\
\hline Accusative & el(s) & la/les & ho & Direct Object \\
\hline Dative & \multicolumn{2}{c}{ li/els } & & Indirect Object \\
\hline
\end{tabular}

Table 3: Etymological pronominal system in Catalan

\section{Research Questions / Hypotheses}

Our research questions are: is there a convergence of the Spanish and Catalan pronominal clitic systems in the spoken language of Majorca? What happens to the structure with the personal preposition $a$ in cases of clitic doubling?

\subsection{Methodology and Data Collection}

Forty Catalan-Spanish bilingual adults participated in this study. We present data from 24 women and 16 men (age range 16-65 years old, $S D=6.3$; mean age $=37.85$ ). Speakers were born in Mallorca, Spain and resided in three major geographic areas of the island: the capital, Palma, and the areas corresponding to the villages of Llucmajor and Capdepera. ${ }^{2}$ This division is important because the speakers' dominant L1, i.e., Majorcan Catalan or Spanish, may vary depending on where they reside.

\footnotetext{
${ }^{2}$ However, there are also three participants from two other villages of Mallorca: Llubí and Sóller.
} 
The data we analyzed came from spontaneous oral production data from all forty participants in the study. Each participant was recorded twice, once in Spanish and once in the Majorcan Catalan variety. Each recording lasted approximately 10 to 15 minutes $^{3}$ and involved a variety of topics, but mainly related to family, hobbies, work and individual anecdotes. The interviews were conducted in the homes of the participants in a very spontaneous and relaxing atmosphere. ${ }^{4}$ Additionally, all participants filled out an ethnolinguistic questionnaire with questions about different extralinguistic variables; they provided information on social variables such as age, sex and area of residence, and on the origin and mother language of their parents.

We analyzed 964 clitic tokens (511 in Catalan and 453 in Spanish), which we have divided into distinct groups. First, we took into account only the clitic doubling structures in which the referent used is [+human] or [+animate], for which we extracted 61 Spanish and 69 Catalan occurrences from the data. The remaining cases were divided considering the case (accusative/dative) and gender (masculine/feminine) of the clitic, yielding three groups in Spanish: one involving le/les (146 tokens), another concerning la/las (81 tokens), and the last one on the use of lo/los (226 tokens). In Catalan, we created four groups: one of them included the indirect object li/els (213 tokens), and three were DO groups, divided by gender: masculine el/els (84), feminine la/les (87) and neutral ho (127). For a general analysis of all the data, we used the SPSS program and we used the same labels for the different analyzed groups: "target like” and "target deviant." "Target deviant" occurrences for clitics included nonetymological use of clitics and omission of the clitic when it should appear. In the clitic doubling structures, we treated as target like cases in which the personal preposition $a$ is used correctly and as target deviant cases in which the personal $a$ is not used when it should appear, or cases in which it is used incorrectly.

\section{Clitic Doubling in the Spanish and Catalan of Mallorca}

As we can see in Table 4, the percentages are very balanced between instances of clitic doubling in which the use of the preposition $a$ occurs as expected, and uses that are not expected in each language:

\begin{tabular}{|c|c|c|c|c|c|c|}
\hline & Target like & $\begin{array}{l}\text { Target } \\
\text { deviant }\end{array}$ & $\begin{array}{l}\text { Standard } \\
\text { deviation }\end{array}$ & p-Value & $\mathrm{F}$ & Sig. \\
\hline Catalan & $\begin{array}{l}41 / 69 \\
59.4 \%\end{array}$ & $\begin{array}{l}28 / 69 \\
40.6 \%\end{array}$ & 49464 & 0.9303 & 3.271 & .044 \\
\hline Spanish & $\begin{array}{l}35 / 61 \\
57.4 \%\end{array}$ & $\begin{array}{l}26 / 61 \\
42.6 \%\end{array}$ & .49863 & & 4.601 & .036 \\
\hline
\end{tabular}

Table 4: Use of personal $a$ in clitic doubling structures in Majorcan Catalan/Spanish

\footnotetext{
${ }^{3}$ However, there are also other recordings that lasted between 30 and 40 minutes in which two of the speakers participated.

${ }^{4}$ For data concerning Peninsular Spanish and Peninsular-Central Catalan, we have used as a control group four participants from a longitudinal study from the University of Wuppertal, Frühkindliche Zweisprachigkeit: Italienisch-Deutsch und Französisch-Deutsch im Vergleich (Early childhood bilingualism: Comparing Italian-German and French-German bilingualism), 1999-2005, University of Wuppertal. These data were used for comparison with permission from the principal investigator, Natascha Müller.
} 


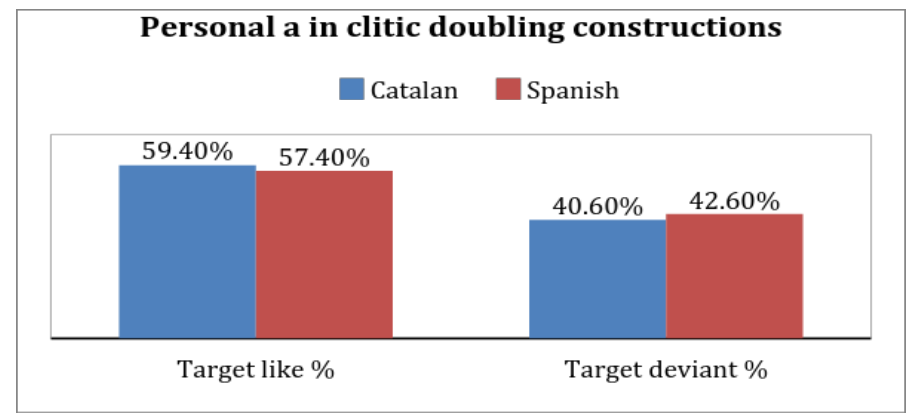

Figure 1: Uses of the personal $a$ in Catalan and Spanish in clitic doubling structures

Given these data, which show a similar distribution of target like and target deviant forms in both languages, we want to determine what external factors could affect the omission of the personal preposition $a$. Considering speaker's sex, women appeared to be more likely than men to omit the corresponding preposition, although this difference was not statistically significant, as we can see in Table 5:

Personal $a$

\begin{tabular}{lccccl}
\hline Sex & \multicolumn{2}{c}{ Target like } & \multicolumn{2}{c}{ Target deviant } & p-Value: \\
\cline { 2 - 5 } & Spanish & Catalan & Spanish & Catalan & 0.2063 \\
\hline Men & $52 / 61$ & $59 / 69$ & $9 / 61$ & $10 / 69$ & Catalan \\
\cline { 2 - 5 } Women & $44 / 61$ & $51 / 69$ & $17 / 61$ & $18 / 69$ & p-Value: \\
& & & & & 0.1422 \\
\hline
\end{tabular}

Table 5: The use of the personal preposition $a$ in clitic doubling structures depending on speaker's sex

However, we found significant differences regarding the linguistic preference of the speakers, and observed that speakers who indicated a linguistic preference for Catalan showed a higher rate of target deviant cases than the ones that indicated a preference for Spanish:

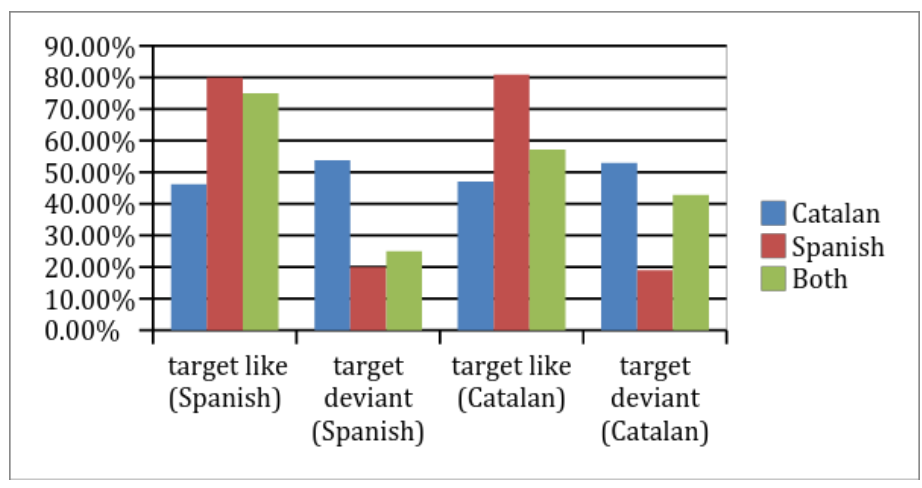

Figure 2: Use of personal $a$ depending on the linguistic preference

More specifically, Table 6 shows the number of tokens and percentages for the groups identified in Figure 2. The rate of target deviant forms is independent of the fact that there were more participants who indicated a linguistic preference for Catalan, as it would be expected given the predominance of Catalan in Mallorca. 


\begin{tabular}{|c|c|c|c|c|c|c|}
\hline \multirow{2}{*}{$\begin{array}{l}\text { Linguistic } \\
\text { preference }\end{array}$} & \multicolumn{2}{|c|}{ Majorcan Spanish } & \multicolumn{3}{|c|}{ Majorcan Catalan } & \multirow{4}{*}{$\begin{array}{l}\text { Sig. } \\
.229\end{array}$} \\
\hline & Target like & Target deviant & \multirow{4}{*}{$\begin{array}{l}\text { Sig. } \\
.036\end{array}$} & Target like & Target deviant & \\
\hline Catalan & $18(46.2 \%)$ & $21(53.8 \%)$ & & $16(47.06 \%)$ & 18 (52.94\%) & \\
\hline Spanish & $8(80 \%)$ & $2(20 \%)$ & & $17(81 \%)$ & $4(19 \%)$ & \\
\hline $\begin{array}{l}\text { Both } \\
\text { languages }\end{array}$ & $9(75 \%)$ & $3(25 \%)$ & & $8(57 \%)$ & $6(43 \%)$ & \\
\hline
\end{tabular}

Table 6: Use of personal $a$ according to speakers' linguistic preference

We have made a comparison according to the different areas where study participants resided, as summarized in Figure 3. The data from Sóller and Llubí were not significant, partly because we only had three participants from those villages. However, we can observe that the patterns are different among the other three areas, Llucmajor, Capdepera, and Palma. In Llucmajor, there is a higher rate of target deviant uses of the personal $a$ in clitic doubling in Catalan than in Spanish. In Capdepera there is an opposite pattern to Llucmajor, with a lower rate of target deviant uses in Catalan than in Spanish. Finally, in Palma the rate of target deviant forms is more balanced between the two languages, although there are more target like than target deviant forms in each language.

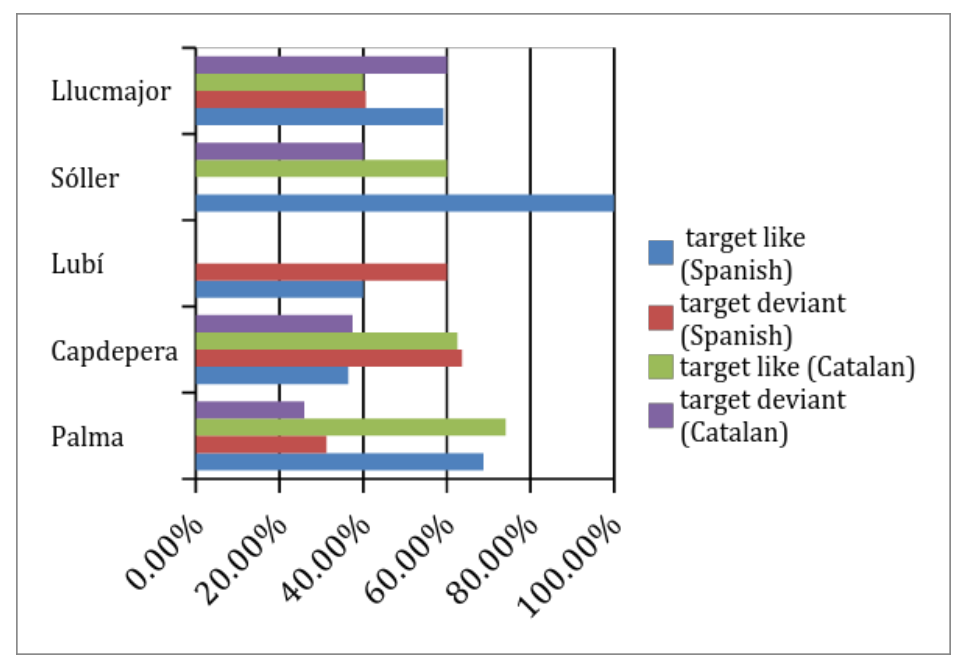

Figure 3: The use of the personal preposition $a$ depending on zone

The results suggest that there is some influence from Catalan on Spanish with respect to the use (or omission) of the preposition $a$ in clitic doubling structures, because there is a higher rate of cases in which the corresponding preposition is not used (target deviant cases) in Spanish in areas where Catalan is more dominant (Capdepera and Llucmajor). We can observe the absence of the personal preposition $a$ in some examples in Spanish (7 a-d) and in Catalan (8 a-b):
a. *Ø ella la cambiaron
'They changed her.'
b. *Ø La Aitana y $\varnothing$ el chico lo veo muy poco
'I rarely see them.'
c. * $\varnothing$ todo le echan química
'They will put chemicals in everything.'
d. *Ø José le gusta hacerlo rabiar
'J. likes to bother him.'

As we can see in these examples, the absence of the preposition occurs both with direct (7a-b) and indirect objects (7c-d) in Spanish. This indicates that there is no full convergence with the pattern found 
in Catalan, since in Catalan the preposition is not used with direct objects of verbs such as elegir, escollir (choose), escoltar (listen), estimar (love), saludar (greet), veure (see), and visitar (visit). However, the pattern of omission in Spanish applies to other verbs. In addition, speakers also omit the preposition $a$ with indirect objects in Spanish, even in cases where it is still used in Catalan.

However, in Majorcan Catalan, target deviant omissions do occur with indirect objects:

$\begin{array}{rr}\text { (8) a. }{ }^{*} \varnothing \text { sa gent li } & \text { va agradar molt } \\ \text { people } 3 p . c l & \text { please much }\end{array}$

'People liked it a lot'

b. Jo imagin que * $\varnothing$ totes ses mares lis deu passar això

I think that (to) all mothers 3p.cl-pl might suffer this

'I think that all mothers might suffer this.'

Additionally, in the Catalan uses, target deviant uses involve not only the omission of the preposition $a$, but also the use of another preposition (en):

\section{(9) En els nins no elzi pots tocar \\ At the children not 3p.pl.cl can touch \\ 'You cannot touch children'}

That is, akin to the example (9), if clitic doubling applies to a referent consisting of a tonic pronoun, then the preposition has to be used in Catalan. However, this doesn't happen in the previous examples of Majorcan Spanish. What might be happening is that the left dislocated DP (without the preposition $a$, (7c-d)), given its position in Spanish, may be sharing properties with the subject argument, allowing the omission of the preposition $a$. However, further investigation is necessary regarding this hypothesis.

Similarly, in the data we analyzed there are other examples where the omission of the preposition occurs below the subject position, although these are less frequent (10). In such cases, an inanimate referent can lead to omission of the preposition $a$, despite the fact that the clitic doubling corresponds to an indirect object.

(10) *Yo Ø mi coche no se lo haría

'I wouldn't have it done to my car'

However, in the uses in which the clitic appears before the DP, the preposition $a$ is used with the clitic doubling. In sum the linguistic factors affecting the omission of the preposition $a$ in clitic doubling vary between Majorcan Catalan and Spanish. Although Catalan may influence the omission of the preposition in Spanish by the bilinguals in Mallorca, there is sufficient evidence that there is no full conversion between the two languages regarding this omission:

(11) Échala a esta

'Dismiss her'

(12) La llevaba a la escuela a mi sobrina

'She brought her, my niece, to the school'

Turning our attention back to the social variables, we can observe in table 7 that not all of them seem to influence significantly the uses of the personal preposition $a$ in clitic doubling structures. We had already seen above the role played by area of residence and linguistic preference. As we consider four different social variables, it turns out that age and area of residence have a significant effect, but only in the case of Catalan.

\begin{tabular}{lll}
\hline Social variables & Spanish & Catalan \\
\hline Sex & .523 & .387 \\
\hline Age & .418 & $.043^{*}(\mathrm{p}$-Value 0.05) \\
\hline Area & .661 & $.011^{* *}(\mathrm{p}$-Value 0.05$)$ \\
\hline Education & .937 & .758 \\
\hline
\end{tabular}

Table 7: Effect of extralinguistic variables on use of the personal preposition $a$ in clitic doubling. 


\section{The Use of Third Person Clitics in the Spanish and Catalan of Mallorca}

As we consider the use of the third-person, non-reflexive clitics in Majorcan-Spanish, we confirm that their production does not vary greatly with regard to the uses considered standard. However, regarding dative pronouns le/les and the pronominal clitics in the accusative, lo/los and la/las, almost all target deviant cases correspond to the omission of these when they should appear, and they do not relate to the phenomena known as loísmo or laísmo.

The results regarding Spanish are not significant (see Table 8), partially because the percentages of target deviant uses are very small, confirming that in Mallorca, the Spanish pronominal clitics of the etymological system are still widely used:

\begin{tabular}{llccc}
\hline $\begin{array}{l}\mathbf{3}^{\text {rd}} \text {-person } \\
\text { clitics }\end{array}$ & Tokens & $\begin{array}{l}\text { Standard } \\
\text { deviation }\end{array}$ & Sig. \\
& Target like & Target deviant &
\end{tabular}

Target like Target deviant

\begin{tabular}{llllllll}
\hline \multirow{3}{*}{ Spanish } & le/ les & $133 / 146$ & $91.1 \%$ & $13 / 146$ & $8.9 \%$ & .28578 & .419 \\
\cline { 2 - 8 } & la/las & $78 / 81$ & $96.3 \%$ & $3 / 81$ & $3.7 \%$ & .19003 & .409 \\
\cline { 2 - 8 } & lo/los & $213 / 226$ & $94.2 \%$ & $13 / 226$ & $5.8 \%$ & .23335 & .985 \\
\hline \multirow{3}{*}{ Catalan } & li/els & $172 / 213$ & $80.80 \%$ & $41 / 213$ & $19.20 \%$ & .39518 & $.013 *$ \\
\cline { 2 - 8 } & la/les & $80 / 87$ & $92.00 \%$ & $7 / 87$ & $8.00 \%$ & .27358 & .906 \\
\cline { 2 - 8 } & el/els & $78 / 84$ & $92.90 \%$ & $6 / 84$ & $7.10 \%$ & .25909 & .240 \\
\cline { 2 - 8 } & ho & $72 / 127$ & $56.70 \%$ & $55 / 127$ & $43.30 \%$ & .49746 & .755 \\
\cline { 2 - 7 } & & & &
\end{tabular}

Table 8: Use of third-person non-reflexive clitics in Majorcan Spanish/Catalan.

As we consider Catalan, we have significant differences only in the IO production in Catalan. As for the other uses of the third-person non-reflexive clitics, the incidence of target deviant forms does not appear to be significant.

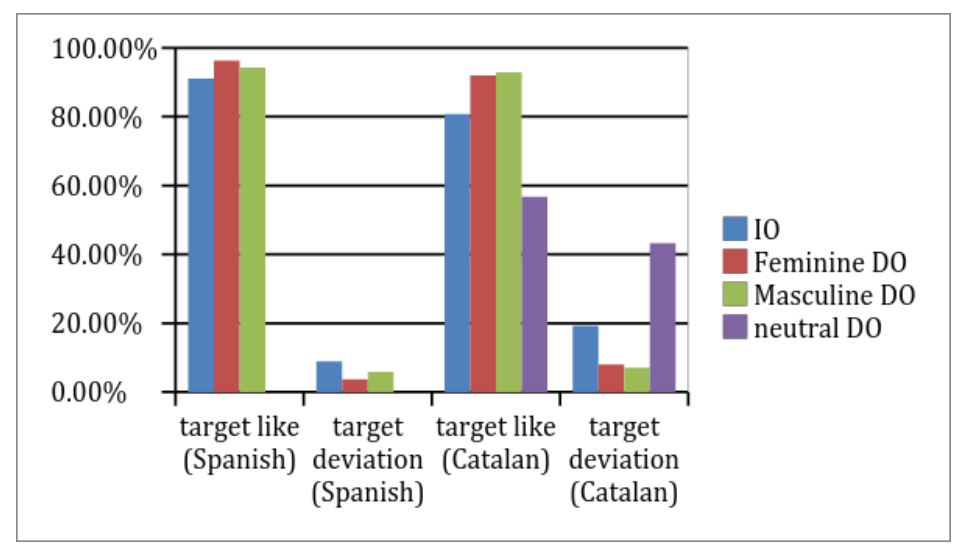

Figure 4: Use of third-person clitics

However, as we can observe in Figure 4, the production of the neutral clitic (ho) in Catalan shows a different picture, with a much higher distribution of target deviant forms, yielding substantial balance between target like and target deviant uses. This clitic seems to have the same semantic extension as the Spanish clitic (lo), that is, the neutral clitic ho in Majorcan Catalan also replaces masculine referents 
(12). However, there are very few examples in which the Spanish clitic $(l o)$ is used as a replacement in Majorcan Catalan.

(12) No ho pots sembrar (el gra)

No lo puedes sembrar (el grano)

'You cannot sow it'

As we take the social variables into account, we can observe in Table 9 that once more only age and area of residence have an influence on the use of the indirect object clitics in the case of Catalan. That is, speakers who are older than 41 produce more "target deviant" forms than the other groups. Considering the area of residence, speakers from the villages, unlike speakers from Palma, present more variation in the uses of the IO clitics in Catalan (plural forms such as les, els, elzi). The differences between Peninsular Catalan and Majorcan Catalan have to do with these varying forms in the latter, instead of being due to a replacement of referential by etymological forms. More specifically, the "target deviant" uses involve the addition of an epenthetic vowel in the plural IO form (elzi/elze).

\begin{tabular}{|c|c|c|c|c|c|c|c|c|}
\hline \multirow{4}{*}{$\begin{array}{l}\text { Social } \\
\text { variables }\end{array}$} & \multicolumn{8}{|c|}{ Third-person clitics } \\
\hline & \multicolumn{3}{|c|}{ Sig. (Spanish) } & \multicolumn{3}{|c|}{ Sig. (Catalan) } & \multirow{3}{*}{$\begin{array}{c}\mathrm{DO} \\
\text { (masc.) }\end{array}$} & \multirow{3}{*}{$\begin{array}{c}\mathrm{DO} \\
\text { (neutral) }\end{array}$} \\
\hline & \multirow[t]{2}{*}{ IO } & \multirow[t]{2}{*}{$\begin{array}{c}\text { DO } \\
\text { (fem.) }\end{array}$} & \multirow[t]{2}{*}{$\begin{array}{c}\mathrm{DO} \\
\text { (masc.) }\end{array}$} & \multicolumn{2}{|r|}{ IO } & \multirow[t]{2}{*}{$\begin{array}{c}\text { DO } \\
\text { (fem.) }\end{array}$} & & \\
\hline & & & & Sig. & p-Value & & & \\
\hline Sex & .841 & .548 & .245 & .822 & & .688 & .496 & .450 \\
\hline Age & .937 & .347 & .676 & .023 & $.05 *$ & .175 & .202 & .437 \\
\hline Formation & .204 & .789 & .106 & .838 & & .641 & .759 & .237 \\
\hline Area & .719 & .732 & .329 & .000 & $.01 * *$ & .120 & .523 & .528 \\
\hline
\end{tabular}

Table 9: Social variables related to third-person clitics

With regard to linguistic preference, the data show (Table 10) again that the IO clitic production is affected in Catalan. Speakers who have Catalan as their linguistic preference use the vernacular (target deviant) Majorcan Catalan forms more frequently:

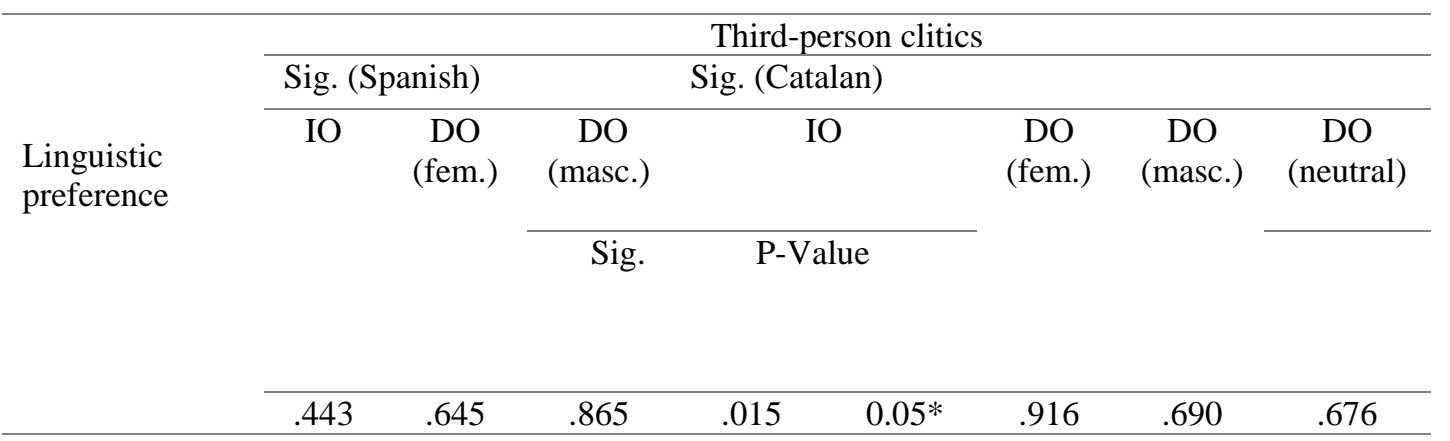

Table 10: Relationship between use of third-person clitics and linguistic preference

\section{Final Remarks}

The aim of this study was to test whether or not bilingual speakers of Spanish-Catalan in Mallorca use the corresponding preposition $a$ in clitic doubling structures when the referent is human or animate. In addition, we considered briefly the distribution of third-person, non-reflexive clitics. After analyzing 
data from forty participants, we have found that Catalan seems to influence the production of these structures in Spanish, especially regarding the omission of the preposition. However, this omission does not occur in the same type of structures in Spanish as in Catalan. Bilingual speakers from Mallorca seem to follow another pattern: they omit the personal $a$ when the DP that is the target of clitic doubling contains a tonic pronoun and is left-dislocated. However, this does not occur in cases in which the DP that is the target of clitic doubling follows the clitic. In previous studies such as Guijarro-Fuentes and Marinis (2009), a different pattern was observed among the Spanish-Catalan bilinguals from Barcelona, who made more commission errors than omission errors with the preposition, unlike what happens in Mallorca. With regard to the linguistic preference of the speaker, in Spanish this variable affected the rate of target deviant clitic doubling structures, yielding primarily a higher rate of omission of the personal preposition $a$ in these structures.

Turning to the production of third-person, non-reflexive clitics, we observed that the few target deviant errors in Majorcan Spanish involved the omission of the clitic, especially in the accusative case, although these occurrences were not significant. In Majorcan Catalan, the most prominent target deviant cases (as compared to the expected forms in Peninsular-Central Catalan) did not involve clitic omission as in Spanish, but rather the semantic extension of the neutral clitic ho to refer to either neutral or masculine referents, similarly the clitic lo in Spanish.

With regard to social variables that were significant, the linguistic preference of the speaker influenced the use of some third-person clitic variants. In Catalan the speaker's linguistic preference correlated with differences in the use of IO third-person clitics. Speakers who had Catalan as their linguistic preference presented a higher rate of target deviant uses of indirect object clitics. The age and area of residence of the participants affected the rate of such target deviant forms as well. Older speakers and speakers from the villages also produced a higher rate of target deviant forms of indirect object clitics in Catalan.

Thus, we observe patterns that are affected by bilingualism in an area where two languages coexist. There is some syntactic convergence in the properties of clitic doubling, which seems to extend to the omission of the preposition in many cases and also the simplification in the use of the two DO clitics in Catalan ( $e l$ and $h o$ ) with ho referring to the same referents as lo in Spanish.

We need to collect more data on bilingual speakers of Mallorca whose linguistic preference is Spanish versus speakers whose preference is Catalan, to try to determine more specifically whether the omission of the preposition is a widespread pattern in certain structures and if the omission of clitics, and others, could also be the beginning of a language change on the island.

\section{References}

Anagnostopoulou, E. (2006). Clitic doubling. In Martin Everaert and Henk van Riemsdijk (Eds.). The Blackwell Companion to Syntax, vol. 1, Oxford: Blackwell, 519-580.

Fernández-Ordóñez, I. (2001). Hacia una dialectología histórica: Reflexiones sobre la historia del leísmo, el laísmo y el loísmo. Boletín de la Real Academia Española, 81(284), 389-464.

Fischer, S. (2003). The Catalan Clitic System: a diachronic perspective on its syntax and phonology. Berlin: Walter de Gruyter.

Guijarro-Fuentes, P., \& Marinis, T. (2009). The acquisition of personal preposition a by CatalanSpanish and English-Spanish bilinguals. In Selected proceedings of the 11th Hispanic Linguistics Symposium, 81-92.

Perea, M. P. (2012). Les combinacions de clítics pronominals en els dialectes catalans. In Estudis Romànics, 34, 99-143.

Roca, F. (1992). Object clitics in Spanish and Catalan. Catalan Working Papers in Linguistics 2, 245-280. 
Sinner, C., \& Wesch, A. (2008). El castellano en las tierras de habla catalana. Berlin: Iberoamericana.

Todolí, J. (1998). Els pronoms personals. València: Universitat de València.

Urrutia Cárdenas, S. H. \& Ulloa, T. F. (1997). Supresión del clítico acusativo de tercera persona en el español: América y País Vasco. A D. Rodolfo Oroz, in memoriam. Boletín de Filología, 36, 287. 